\title{
LA DINAMICA DE LA LIBRE APRECIACION DE LA PRUEBA EN LA JURISDICCION CIVIL
}

\author{
Por José Rodríguez Espejo \\ Dr. en Derecho por la Universidad de Bolonia
}

S U M A R I O

1. Planteamiento. Dificultades que se oponem e este estudio:

a) Intrínseca.

b) Extrínseca.

2. Medios de prueba.

3. Materia de prueba. Crítica de la tradicional distinción de la prueba en directa, histórica y crítica.

4. Motivos de prueba.

5. Actos de asunción de prueba.

6. Reglas de experiencia.

7. Fuentes de prueba:

a) En la prueba directa o representativa.

b) En la prueba representativa.

c) En la prueba indiciaria.

8. Conclusiones.

1. PLANTEAMIENTO. DIFICULTADES QUE SE OPONEN A ESTE ESTUDIO

A) Intrinseca. B) Extrinseca.

La libre apreciación de la prueba - lo revela magníficamente su significación etimológica (1) y están conformes en

(1) En efecto, las dos palabras (valoración y apreciación) que sirven para indicar el concepto hacen perfectamente clara la idea de que la valoración de la prueba es una actividad espiritual que fija los he- 
admitirlo todos los autores - es una actividad espiritual que concluye con un juicio. Aparentemente un hecho muy fácil: juicio - dicen los tratados clásicos de Lógica - es el acto por el que la mente afirma la conveniencia o disconveniencia de un predicado con un sujeto (2). Sin embargo, si intentamos profundizar en su estructura, si nos adentramos en el estudio paciente de su dinámica, no podemos menos que asombrarnos de su radical complejidad. Basta para ello que nos propongamos el ejemplo más simple: Un día en una conversación cualquiera alguien dice: "Pedro es mi amigo". Evidentemente un juicio. Pero detengámonos un instante, pensemos por un momento intentando reconstruir el proceso que ha llevado a este caballero a hacer esta afirmación y, súbitamente, nos percataremos de la complejidad escondida tras la aparente simplicidad del fenómeno.

¿Qué ha sucedido?; o mejor, ¿qué ha tenido que suceder para que una afirmación tan sencilla haya sido formulada? Tras unos instantes de reflexión, la respuesta no parece ya tan fácil. Vagamente vamos intuyendo que todo un mundo de fonómenos psíquicos alimentan y están en la base de una tan simple aseveración; el caballero primeramente ha individualizado a Pedro - esto implica relacionar sensaciones y percepciones mentales que puedem resultar extraordinariamente complejas - despues ha afirmado de él que es su amigo - y aquí otra vez enlaza sensaciones y percepciones, recuerdos y fantasmas, coordinándose entre sí y siendo objeto de valoración y crítica (3) - Así pues, vagamente intuímos una serie innumerable de fenómenos y que con dificultad a costa de mil esfuerzos y después de mil huídas, logramos imperfectamente someter a nuestro análisis.

chos controvertidos mediante la determinación de la eficacia de los medios de prueba empleado en el proceso. Valorar la prueba (de valor-oris) quiere decir fijar su valor, determinar su eficacia. Apreciar la prueba (de ad-pretium) es la misma cosa.

(2) G. Márquez: Introducción a la Filosofia. Madrid, 1945, 5.a ed., pág. 21.

(3) Gozzano: Compendio de Pschiatría. Torino, 1954, 4.a ed., pág. 5. 
A pesar de todo no podemos detenernos ante los obstáculos; el juicio es no sólo un resultado, sino también la actividad a través de lacual éste se obtiene, y sin el estudio paciente de su dinámica, sin la observación minuciosa del proceso a través del cual se desenvuelve y actúa, no podremos comprender la totalidad del fenómeno, ni en modo jugoso y vital completar el trabajo analítico que hemos anunciado para después. Así nuestra investigación sería tan sólo un frío preparado anatómico con capacidad de mostrarnos la estructura del brazo, pero no para que nos formemos idea cabal del vibrante movimiento del espadachín.

Urge, pues, realizar este trabajo y en él vamos a adentrarnos conscientes, tanto de sus enormes dificultades como de nuestras muchas limitaciones.

Las dificultades que obstaculizan y hacen especialmente penosa nuestra tareia son dos: una de carácter intrínseco, inherente a la naturaleza misma de este tipo de estudios; otra de carácter contingente, derivada de la materia específica que hemos escogido como argumento.

A) Desde el primer punto de vista a nadie puede extrañar que digamos - es verdad indiscutida - que cómo por su propia estructura le mente humana tiende a ocuparse de los seres en reposo, el estudio de toda realidad dinámica resulta siempre penoso e imperfecto.

Para el hombre el movimiento no es generalmente algo que "es", sino algo que "deviene"; sencillamente lo que se desliza entre una situación anterior y otra posterior diferente. Por ello, el cambio, el proceso, la acción no podemos imaginarlos sino como un sucederse, como el paso de un estado primario a otro subsiguiente y distinto. De ahí, digo, las dificultades del estudio de la dinámica de cualquier fenómeno que no pueden superarse. La mente humana estudia sólo realidades que se dejam aprehender. El movimiento, por el contrario, escapa, por su dinamicidad, a su análisis. Pero del mismo modo que una serie de fotografías proyectadas a un cierto ritmo producen sensación de movimiento, el análisis de las distintas eta- 
pas que componen la apreciación puede también explicarnos su proceso.

B) En segundo lugar, por la naturaleza especial de este estudio nuestro examen de la dinámica de la actividad probatoria no puede ser realizado con la perfección que sería de desear. Lo ideal en este caso, puesto que la descripción perfecta del movimiento hay que hacerla no más fenómenológicamente posible, sería ir siguiendo paso a paso el desenvolverse de todos los fenómenos probatorios que tienen repercusión. Sólo así, observando con minuciosidad la realidad concreta que ante nosotros se desarrolla, reflejando con exactitud las distintas fases por las que el proceso de la libre apreciación de la prueba atraviesa, el fenómeno dinámico queda captado.

Pero esto, desgraciadamente, por las exigencias de ser nuestro estudio de derecho comparado, no podemos realizarlo. La libre apreciación de la prueba y, en modo genérico, la instrucción probatoria regulada en el Derecho italiano, es profundamente diversa a esta fase del proceso en el Derecho español. Ello hace, naturalmente, que si queremos hacer una descripción de la dinámica de la libre apreciación común a ambos ornamientos jurídicos, nuestro estudio tiene que ser menos fenómenológico de lo que sería deseable; tiene que prescindir de lo que en cada actividad hay de personal y singularísimo para detenerse sólo en las categorías conceptuales elaboradas sobre las diferencias, con lo que se percibe el común y fundamental a todas ellas (4).

Lo que sería, pues, el estudio de un movimiento, queda así convertido en el examen de un simple esquema de movimiento. Pero también esto tiene su importancia y su valor. Cierto que el análisis pierde así exactitud, pero también gana claridad y

(4) En efecto; efectuar un estudio completo de la dinámica de la valoración libre de la prueba en la jurisdicción civil italiana y espanola implicaría el estudio total de la instrucción en ambos ordenamientos jurídicos. Y esto, naturalmente, sería excesivo a los fines propuestos. 
sencillez. Simplificado, sin duda, desprovisto de elementos no esenciales, el movimiento, no obstante, se percibe. Queda claro, pues, que por exigencias del tema escogido presentamos aquí sólo un esquema de la dinámica de la libre apreciación de la prueba en la jurisdicción civil. Pero tenemos casi la presunción de creer que de este modo nuestro estudio ganará en claridad, sin perder nada de la exactitud, que ha sido el ideal a cuya obtención tendió siempre nuestro esfuerzo.

Al comezar este capítulo hablamos de la terrible complejidad que se escondía tras la aparente sencillez de un simple juicio, y poco antes (cap.I) insinuamos que para la perfecta comprención de la apreciación de la prueba era necesario partir del estudio de fenómenos psíquicos que están en su base, pero se desenvuelven con anterioridad en el tiempo. El juicio, dijimos, se nutre de sensaciones y percepciones sin las cuales no puede concebirse. Con ello queda claro que la apreciación que es un juicio, si quiere ser suficientemente entendido en su proyección dinámica, es necesario que para su estudio se parta de mojones que están más acá de lo que es libre valoración de la prueba en sentido estricto. Sólo así el mecanismo íntimo de este proceso lógico queda totalmente desvelado (5).

Hecha esta aclaración que estimábamos necesaria, vamos ocuparnos del tema. Nuestra actitud es clara; la prueba - la de cualquier proceso, un proceso ejemplar, paradigmático ante nosotros. Con la inteligencia tensa, como el cazador en acecho sus sentidos, observaremos atenta, objetiva, penetrantemente, el fenómeno para intentar captar arcanos secretos de su estructura. Si la libre apreciación de la prueba es un juicio, veremos cómo se forma, cómo va constituyéndose poco a poco, cómo penosamente cual un embrión o aquel fantástico "Hombre Invisible" que hace algunos años nos presentó el cine, va pasando de un estadio de su devenir a otro más perfecto y tomando paulatinamente forma y figura. De este modo minucioso y cuidado realizaremos la disección del fenómeno. Así, len-

(5) Gozzano: Ob. cit., págs. 3 y ss. 
tamente, iremos examinando las distintas fases del proceso. Paso a paso seguiremos nuestra tarea; aislaremos conceptos, individualizaremos piezas del mecanismo, advertiremos engranajes y nos percataremos del ordenado funcionamiento del todo. De esta forma, lo que es ahora mero movimiento - caos puro para la inteligencia - encontrará, después, explicación y sistema. Sin más dilaciones, llemos de buenos deseos, esta tarea es la que vamos a intentar realizar.

Afirmación cardinal a lo largo de este estudio es la de que la libre apreciación de la prueba constituye una operacion mental, para cuya comprensión es necesario partir de las percepciones, sensaciones y conocimientos genéricos que suministran al órgano decisor los elementos necesarios para elaborarla. Veamos, pues, pacientemente cómo va formándose este proceso en la mente del órgano jurisdiccional del Estado. Para ello nada más adecuado que una observación atenta de la realidad procesal.

He aquí un lítigio, un proceso civil típico ante nosotros. Sabemos que, por regla general, la jurisdicción civil no se mueve sino a instancia de parte. Pues bien: una parte, en conflicto más o menos violento con otra, acude al órgano jurisdiccional del Estado solicitando de él la decisión de la controversia. La otra, que también pretende tener razón, se opone decididamente a sus exigencias. Una lucha jurídica queda, así, perfectamente entablada; de un lado, las partes desenvolviendo en el modo legalmente señalado contrapuestas pretensiones; de otro, el órgano jurisdiccional que, solicitado a decidir de manera diversa, tiene que resolver, al fin, conforme a Derecho.

Por ello, puesto que el Derecho en su estructura lógica es un conjunto de normas hipotéticas, si se solicita su actuación es porque se entiende que el supuesto de hecho previsto en la norma abstracta se ha realizado en la realidad concreta. Base de las pretenciones de las partes es, así, un fundamento fáctico y una razón jurídica, un hecho que se afirma existente y una norma jurídica que tal hecho prevee y regula. De este mo. do, lo fundamental de la función del Juez en el proceso es decidir la controversia aplicando al supuesto de hecho la norma 
jurídica pertinente (6). Para ello necesita, primeramente, conocer la norma, después, conocer el hecho.

Por regla general, el conocimiento del Derecho se presume en el Juez, de modo que tiene que aplicar la norma jurídica adecuada sin que su existencia se le haya probado con anterioridad. Las excepciones a este principio genérico - plasmaảo con palabras latinas en el famoso aforismo: dabo tibi ius - son sobradamente conocidas para que nos detengamos en su estudio y exposición (7). Principio opuesto - da mihi factum - rige en materia de hechos; el Juez no puede en ningún caso poner, como fundamento de su decisión, un hecho que no le haya sido alegado por las partes, ni su examen proyectarse más allá de la minúscula porción de realidad sometida a su observación (8).

(6) En este párrafo, muy esquemãticamente, hemos insinuado muchos problemas de importancia fundamental en la ciencia del proceso. Cada uno de ellos cuenta con abundante bibliografia. Para no hacer la lista interminable, nosotros nos limitaremos aquí a dar simplemente los nombres de los autores de obras generales italianas y espanolas por nosotros consultadas en cuyas páginas será posible encontrar las ampliaciones necesarias: ANDRIOLI, CALAMANDREI, CARNELUTTI, D'ONOFRIO, CHIOVENDA, LIEBMAN, MORTARA, REDENTI, SATTA, ZANZUCHI, FÁBREGA, GOMEZ ORBANEJA, PLAZA y PRIETO-CASTRO. En relación al principio del poder dispositivo de las partes existen páginas muy interesantes de CARNACINI: 'Tutela jurisdiccional y técnica del proceso, "Revista de la Facultad de Derecho de Méjico", t. 3.॰, num. 12, págs. 119 y ss.

(7) V. CARNELUTTI: Sistema di Diritto processuale civile. Padova, 1936, t. $1 .^{\circ}$, páginas 676 y ss., e Instituzioni del proceso civile italiano. Roma, 1956, 5.a edición, t. 1. ${ }^{\circ}$, págs. 212 y ss.; GUASP: Comentarios a la Ley de Enjuiciamiento civil. Madrid, 1947, t. 2. ${ }^{\circ}$, v. I. part. 2.a págs. 374 y ss., y Derecho..., págs. 355 y ss.; PRIETO-CASTRO Manual de Derecho procesal civil. Zaragoza, 1954, t. $1 .^{\circ}$, páginas 302 y ss.

(8) En relación a este tema, aparte naturalmente de las obras generales con anterioridad citadas, puede consultar-se CALAMANDREI: Il giudice e lo storico, en "Riv. Dir. Pro. Civ." I, págs. 105 y ss. y Per la definizione del fatto notorio, "Riv. Dir. Pro. Civ.", A. 11, núm. 4, part. 1.a, págs. $273 \mathrm{y}$ ss.; MAZZARELLA: Appunnti sul fatto nottorio. “Rev. Dir. Pro. Civ.", A. XI núm. 2, par. 2a. páginas 65 y ss; SCANDIANI: Patologia della posizione del fato nel processo. "Riv. Dir. Pro. Civ.", A. VIII, núm. 7, part. 2a. págs. 74 y ss. 
En todo caso, no basta que el Derecho o, en su caso, la norma jurídica a él aplicable sean alegados. Es necesario, además, que ante el órgano jurisdiccional del Estado uno y otro aparezcan como jurídicamente ciertos. En la jurisdicción civil, donde tan amplia aplicación tiene el principio dispositivo, esta exigencia de certidumbre viene en gran parte satisfecha por el instituto de la admisión (9). Pero cuando, a pesar de todo, los hechos no han sido fijados por la conformidad en su existencia de las partes, se exige una actividad ulterior, que tiende a obtener dicha fijación. Esta actividad es precisamente la prueba.

Como para el objeto de nuestro estudio carece de interés, prescindamos ahora de la carga de la prueba (10) y de la intervención de las partes en la instrucción probatoria. Fijemonos tan sólo en aquellos aspectos del fenómeno, cuya observación nos ayudará, iluminando vertientes y facetas, al mejor entendimiento de la libre apreciación.

\section{MEDIOS DE PRUEBA}

Para ello partamos de esta afirmación fundamental: el órgano jurisdiccional tiene que establecer, que determinar, como juridicamente cierto un hecho. Objeto de la actividad probatoria - no podemos olvidarlo - son siempre hechos; incluso cuando hay que probar una norma, no es el Derecho en sí el tema de prueba, sino, inmediatamente y ante todo, el hecho de su existencia. Esta es una verdad que conviene considerar atentamente, porque interesa para deducir de ella sus naturales e importantes consecuencias.

(9) V. CARNELUTTI: La prova civile, 2.a ed., págs. 16 a 33; CALAMANDREI: Il giudice e... cit.; BETTI: Sul valore juridico dell'ammissione del procuratore e sui poteri del giudice di casazione. "Riv. Dir. Pro. Civ.", A. part. 2a., páginas 189 y siguientes.

(10) V. ANDRIOLI: Commento, t. 1.º pág. 300 y ss.; CARNELUTTI: Teoría generale del Diritto, 3a. ed. Roma, 1951, pág. 450, y La prova civile, págs. 30 y siguientes; MICHELI: L'onere della prova, $\mathrm{Pa}$ dova, 1942; AUGENTI: L'onere della prova. Roma, 1932. 
Ante todo no olvidemos que el hecho, por su propia estructura óntica, es algo que acontece en un punto cualquiera de las coordenadas espacio-tiempo; es decir, un evento que sucede aquí y ahora, allí y entonces. Inútil será, pues, que alguien desee portar, ante el órgano jurisdiccional del Estado, el hecho que tiene interés en demonstrar, porque su intento terminará en fracaso. El hecho es, por su propia esencia, inaprensible e inaferrable; si se coloca como fundamento de una pretensión, quiere decir que ha pasado ya, que existió en un momento anterior del tiempo, pero ya no existe, no puede existir, sino en concepto de cualidad duradera de una persona 0 de una cosa (11).

Esta simple afirmación está preñada de importantes consecuencias. Por de pronto es evidente que, para determinar como jurídicamente ciertos los hechos de carácter extraprocesal relevamos en el proceso, el órgano jurisdiccional del Estado ha de servirse siempre, y en todo caso, de personas o de cosas (12). No existe otra posibilidad; las personas 0 las cosas son, primariamente, los únicos medios de prueba conocidos.

Para que nos percatemos de la exactitud de esta afirmación, basta la atenta observación del proceso. ¿Qué es lo que hace, en efecto, el Juez que desea cerciorarse de la veracidad de los hechos afirmados por las partes, sino interrogar a éstas, examinar testigos e inspeccionar documentos, cosas o persoras? Toda su labor posterior, el juicio que, en definitiva, después forme, estará, en primer lugar, determinado por los elementos que le suministran estos medios de prueba: en principio siempre una persona o una cosa.

(11) El hecho ciertamente sólo puede perdurar como tal hecho en cuanto se injerte en una persona o cosa en concepto de cualidad duradera de esa persona o de esa cosa.

(12) Ante la fugacidad radical del acaecer, pura dinamicidad, el Juez sólo puede servirse para la fijación de lo que es simple devenir impermanente, de lo permanente; es decir, de la persona o de la cosa. 
Sin embargo, pese a la aparente evidencia del fenómeno, son pocos los autores que formulam un concepto tan sobrio $\mathrm{y}$ esquemático del medio de prueba (13). Los más, y entre ellos se cuentan no pocos de los nombres más prestigiosos de la ciencia del proceso, hacen, por el contrario, entrar en la definición elementos que pertenecen a categorías conceptuales diferentes y que más tarde estudiaremos. Para nosotros, pues, queda claro que medio de prueba es la persona o cosa que suministra al órgano jurisdiccional del Estado los conocimientos necesarios para que pueda determinar la verdad o falsedad jurídica de un hecho (14).

Esta definición, sin embargo, tiene carácter puramente aproximativo; su exacto entendimiento exige que efectuemos ahora ulteriores puntualizaciones.

Los hechos objeto del tema de prueba pueden ser probados, bien mediante las aportaciones de carácter presentativo o representativo del hecho a probar efectuadas por las personas o cosas que gozan de la condición de medios de prueba, bien mediante la justificación de hechos distintos de los que constituyen el tema probatorio y de cuya existencia puede deducirse la existencia de éstos.

Estos hechos, que genéricamente podríam denominarse hechos indiciarios, tienen, también, en la inmensa mayoria de

(13) Así, por ejemplo, en la Prueba civil, CARNELUTTI considera medio de prueba la actividad del Juez - percepción y dedución mediante la cual investiga la verdad del hecho a probar; REDENTI: Diritto Processuale Civile. Milano, 1953, t. II, pág. 57: GUASP: Derecho procesal, Madrid, 1956, página 365; PLAZA Derecho procesual civil, 3a. ed., Madrid 1954, t. 1. ${ }^{\circ}$, pág. 465. V. también lo que dijimos en la nota 6 .

(14) Sin embargo, es necesario advertir que en ciertos casos de prueba crítica, en los cuales el hecho a probar no coincide con el tema de prueba - conducta procesal de las partes, confesión tácita, etc. es el propio hecho en el preciso momento de su actuarse el que se encuentra ante el órgano jurisdiccional del Estado. En estas hipótesis, como veremos después, puesto que medio de prueba $\mathbf{y}$ hecho a probar coinciden, se podria incluso hablar del hecho mismo como medio de prueba. 
los supuestos, carácter extraprocesal, acaecen en una encrucijada de las coordenadas espacio-tiempo ajena al proceso, y su prueba se efectúa al modo ordinario, mediante intervención de los normales medios de prueba. Ello sucede, por ejemplo, con la comprobación de la enemistad existente y las amenazas cruzadas entre dos personas, una de las cuales ha sido asesinada, indicios que, unidos a otros, puedem ayudar al esclarecimiento del objeto probatorio: el asesinato realizado.

Pero el proceso tiene también su historia. Una historia en muchos casos complicada por el cruzarse y entrecruzarse de multitud de hechos de la más varia condición y naturaleza, que no son, dentro de él, pasado cuya existencia necesita ser justificada, sino presente vivo que no precisa comprobación. Son, pues, hechos no reconstituídos en el juicio, sino que constituyen su esencia, que forman y conforman su contenido.

De esta masa ingente de acaeceres - actos en la mayoria de los casos - sólo unos pocos pueden servir para aportar elementos probatorios al órgano jurisdiccional del Estado. Pero, obsérvese bien, la aportación en este supuesto se efectúa ro mediante personas o cosas que de algún modo presentan o representan un hecho extra-processal, sino a través del hecho mismo, contenido del proceso, presente ante el órgano jurisdiccional.

En este sentido, y sólo en él, dejaría de ser aventurado hablar, junto a las personas y cosas, de los actos como medio de prueba (15), y encontraríam su justa calificación actividades procesales carentes hasta ahora de ubicación acertada. A. esta categoría pertenece la conducta procesal de las partes, fuente de convicción del Juez admitida expresamente en la legislación italiana e inevitablemente vigente, pese al olvido

(15) Así, por ejemplo, en la doctrina espanola, GUASP considera también medios de prueba a aquellos acaecimientos que sirvem para convencer al Juez del dato procesal que se intenta justificar. Sus afirmaciones, especialmente discutibles en lo que afecta a la prueba por presunciones, son, no obstante, significativas. 
del legislador, en todo ordenamiento jurídico y las reproducciones de hechos, de tan frecuente aplicación en el proceso penal.

Así, pues, creemos oportuno corregir la definición anterior en el sentido de considerar, más exactamente, como medios de prueba a la persona o cosa y, excepcionalmente, también, a los hechos, que suministran al órgano jurisdiccional del Estado los conocimientos necesarios para que pueda determinar la verdad o falsedad juridica de un tema de prueba. El carácter puramente instrumental, de dato previo en el examen de la libre apreciación de la prueba, que el análisis del concepto ahora delineado tiene en este estudio, nos inclina a abandonar su tratamiento, cuando apenas si ha sido esbozado y cuando estamos convencidos de la fructífera utilidad que tendría una mayor dedicación a él. Pero éstas son exigencias del tema.

\section{MATERIA DE PRUEBA. CRÍTICA DE LA TRADICIO- NAL DISTINCIÓN DE LA PRUEBA EN DIRECTA, HISTÓRIA Y CRÍTICA}

Necesario es que afinemos ahora nuestra atención, porque estamos llegando a uno de los problemas más delicados de toda la teoría general de la prueba. La observación paciente y minuciosa de la realidad procesal será, como siempre, nuestra actitud. Hemos visto que el órgano jurisdiccional trata, con la prueba, de fijar jurídicamente hechos de relevancia en el proceso. Vimos, también, que para ello se sirve o de personas o de cosas, o por regla general, de personas o cosas conjuntamente. Ahora bien: ¿en qué modo pueden servir los medios de prueba - personas o cosas - para esa determinación de la existencia o inexistencia jurídica de un hecho que el órgano jurisdiccional del Estado tiene necesidad de realizar? ¿Cómo antes consistentes pueden ser útiles para demonstrar algo tanhuidizo e inconsistente como es, radicalmente, el hecho? La respuesta nos la dará también la atenta observación de la función probatoria; los medios de prueba - personas o cosas generalmente - son útiles en cuanto de cualquier forma pre- 
sentan, representan o indican el hecho a probar. Según se trate de un caso o de otro nos encontraremos frente a un medio de prueba directa, un medio de prueba histórica o un medio de prueba crítica.

Aunque parezca una disgresión, puesto que el hilo de nuestro análisis nos ha llevado hasta aquí, tenemos que hacer ahora algunas observaciones en torno a la conocida distinción de la prueba en directa, histórica y crítica. Conocida por todos es, tanto la clasificación en sí como el sentido que cada uno de sus miembros tiene en la doctrina más autorizada, hasta el punto de que, hoy día, puede decirse patrimonio indiscuso de la ciencia del proceso. Nosotros, sin embargo, opinamos que, tal ccmo generalmente viene admitida, esta clasificasión es inadmisible (16).

En efecto, condición esencial para la exactitud y validez científica de una clasificación es su perfecta congruencia con el elemento escogido como criterio clasificador. Precisamente ésta es la fundamental exigencia que no satisface la distinción que venimos comentando. Si distinguimos las pruebas según el medio - persona o cosa por regla general - presente, represente o simplemente indique uno de los hechos del más o menos complejo tema de prueba, habrá, efectivamente, que diferenciar la prueba directa de la histórica y de la crítica. Pero para ser consecuentes con el elemento escogido como criterio clasificador, es necesario que la prueba histórica posea un ámbito más limitado y la prueba crítica más amplio del que generalmente presentan en la doctrina dominante.

Prueba histórica, ciertamente, es aquella que representa un hecho, pero no cualquier hecho, sino sólo aquel que forma parte del tema de prueba. Si el elemento representativo demuestra un hecho a través del cual sólo mediante una presunción puede llegarse a la determinación del que es objeto ấ la prueba, como realmente no suministra una auténtica re-

(16) V. especialmente CARNELUTTI: Sistema... cit., t. 1., págs. 677 y ss., e Instituzioni... cit., t. 1.०, págs. 156 y ss. 
presentación del hecho a probar, sino sólo un indicio, resulta obligado transferirlo a la categoría dela prueba crítica. Sólo así, siendo perfectamente congruente con el criterio escogido para fundamentar la distinción, puede ésta justificarse. La prueba, pues, es directa si presenta un extremo del tema de prueba, histórica, si lo representa; crítica, si lo indica. Para mayor exactitud habría luego que distinguir la prueba crítica representativa de la prueba crítica directa, según el carácter presentativo o representativo del elemento probatório suministrado por el medio de prueba para reconstruir el indicio (17).

Pero podemos también realizar una clasificasión de la prueba según la relación existente entre el medio de prueba y el hecho probado. Observando atentamente el espectáculo del proceso nos percatamos inmediatamente de que en él se prueban o, cuando menos, intenta probarse, muchos más hechos de los que constituyen estrictamente el tema de prueba. Naturalmente, sería contrario a los más elementales imperativos de economía procesal que en un proceso intentasen probarse toda clase de hechos. Por ello sólo se prueban los que son relevantes. $\mathrm{Y}$ son relevantes, aparte de los que constituyen el tema de prueba, todos aquellos cuya demonstración puede llevar al Juez al convencimiento de la existencia de los otros.

Si examinamos la prueba desde este segundo punto de vista, la distinción trimembre queda sencillamente convertida en dual, porque, de un modo inmediato, todos los medios de prueba o presentan o representan simplemente un hecho. Sólo a través de esta afirmación inmediata pueden, más tarde, mediante c! trampolin intelectual de la presunción, indicar la existencia de sucesos que ni presentan ni representan de modo directo. Según el criterio de distinción medio de prueba-hecho probado, la prueba crítica desaparece, sólo hay prueba directa y prueba histórica; más exactamente podríamos hablar de prueba perceptiva y prueba representativa. Por no ser consecuentes con

(17) Estas ideas serán desarrolladas más adelante cuando nos ocupemos de la prueba por presunciones. 
ninguno de los criteros en base a los cuales puede se realizada la clasifidación (18), por confundir arbitrariamente miembros de la una y de la otra (19), es por lo que estimamos errónea la distinción a la que venimos refiriéndonos, entendida en el modo que lo hace la doctrina dominante.

Dicho esto, que nos parecia obligado, y aunque el interés del tema tal vez hubiera exigido una crítica más detenida y extensa, para no hacer demasiado grande la disgresión reemprendemos aquí el hilo del discurso.

Parece evidente que al órgano jurisdiccional del Estado no le interesa el medio de prueba - persona o cosa - considerado en su totalidad, sino parcialmente, es decir, sólo en cuanto posee y le proporciona un elemento que presenta, representa o indica el hecho a probar. El testigo, por ejemplo, no interesa al Juez, sino en cuanto estuvo presente en la conclusión del contrato y puede proporcionarle la representación del acuerdo. El vestido manchado de sangre tiene para él el único interés de indicarle la posible existencia de heridas en quien lo portaba. De um modo inmediato, pues, al órgano jurisdiccional no interesa el medio de prueba, sino sólo un elemento muy caracterizado de él. Necesario, pues, resuita distinguir, y esto tampoco aparece hecho con nitidez en la doc-

(18) No es congruente con el primero - es decir, con el criterio medio de prueba-tema de prueba - porque la prueba histórica tal como es entendida comprende, tanto representaciones del tema de prueba como simples indicios del mismo y porque la prueba crítica, definida de aquella forma, no abraza más que uno de sus tipos; es decir, la prueba crítica presentativa. $Y$ no es tampoco congruente con el segundo - o sea, con el criterio medio de prueba - hecho probado porque introduce en la clasificación la prueba crítica que, desde este punto de vista, carece en absoluto de relieve, al tiempo que no hace entrar en la prueba presentativa un elemento que le es propio: la prueba crítica presentativa.

(19) Así, por ejemplo, la prueba histórica entendida de esta forma sería perfecta en una clasificación hecha desde el punto de vista del medio de prueba-hecho probado. Pero es absolutamente incongruente colocada eu una división en la cual algunos de sus miembros. están establecidos en atención al criterio medio de prueba-tema de prueba. Lo mismo podría decirse retorciendo el argumento. 
trina (20), el medio de prueba del elemento de carácter presentativo, representativo o indicativo del hecho a probar que aquél contiene y por el que, fundamentalmente, posee relevancia.

Supuesta la necesidad de efectuar esta distinción, debemos, inmediatamente, encontrar la palabra que, siendo suficientemente expresiva, sirva para indicar sintéticamente el concepto. Nosotros creemos lo más adecuado hablar de materia de prueba, para designar la nueva categoría así delimitada (21). No se crea, sin embargo, que la elaboración de este concepto es un puro juego intelectual realizado con el único fin de efectuar una placentera elucubración. Nada más lejos de la verdad y de nuestros propósitos. De la verdad, porque nosotros no hemos hecho otra cosa que recoger y elevar a categoría, para mejor comprender la totalidad del fenómeno, un elemento que ya estaba perfectamente individualizado en la realidad. La prueba es que, en los casos en que la distinción aparece de modo más evidente, hasta en la prática existen palabras que designan de modo distinto elementos que son clara-

(20) Desde hace tiempo y especialmente después de las fundamentales aportaciones de CARNELUTTI al estudio de las funciones de la prueba, se viene hablando en esta materia de los elementos presentativos, representativos o indicativos del tema de prueba que el examen de los medios proporciona al Juez. Pero ni existía unanimidad desde el punto de vista terminológico (CHIOVENDA habla de medios: Principios de Derecho procesal civil, Madrid, 1922, t. II, páginas 315 y ss.; CARNELUTTI, de fuentes: Prova civile, 2.a ed., págs. 07 y ss.; GUASP, de medios: Derecho... cit., pág. 347; PRIETO, de materia: Manual... cit., pág. 301) ni existía siquiera precisión desde el punto de vista rigurosamente conceptual (v. también estos autores en las páginas citadas). $\mathrm{Y}$ esto sin contar el gran número de autores - entre ellos, algunos de los más prestigiosos cultivadores de la ciencia del proceso - que no creen necesario distinguir con nombres diversos los diferentes elementos que se perciben en los medios de prueba (por ejemplo, REDENTI: Ob. cit., pág. 56).

(21) No utilizamos la palabra medio porque es más conocida, más consagrada en el otro sentido. Y no empleamos la voz fuente, porque incluso el mismo CARNELUTTI, en obras posteriores a su Prova civile, por ejemplo las Instituciones, la utiliza en el sentido que nosotros creemos preferible. 
mente diversos. Así, por ejemplo, se habla de confesión y con$f \in$ 'sante, de testigo y de testimonio.

De nuestros propósitos, porque nada sería tan perturbador en una labor con deseos de ser auténticamente científica.

Así, pues, una cosa es el medio de prueba y otra la materia de prueba. Si aquél lo definimos como la persona, cosa o acción que suministra al órgano jurisdiccional los elementos necesarios para que pueda determinar la verdad o falsedad jurídica de un hecho, ésta la podemos definir diciendo que es elemento o elementos, de carácter presentativo, representativo o indicativo del hecho a probar, que, suministrados al órgano jurisdiccional por una persona o una cosa, le impulsan a fijar la verdad o falsedad jurídica del tema de prueba. Un más profundo estudio y una definición más perfecta de tan interesante materia serán realizados más adelante, cuando nos ocupemos del contenido - juicio valorativo - de la apreciación. Por ahora nos basta con este ligerísimo esbozo. (22).

\section{MOTIVOS DE PRUEBA}

Con dificuldad, pues, porque la materia es extraordinriamente complicada y difícil, vamos poco a poco, paso a paso, avanzando. Hemos visto ya cómo, para determinar jurídicamente los hechos que sirven de fundamento a las pretensiones de las partes, el órgano jurisdiccional del Estado se sirve normalmente de personas o de cosas. Vimos también, cómo dichos medios son útiles, en cuando suministran al Juez un elemento presentativo, representativo o indicativo del hecho a probar que hemos designado con el nombre de materia de prueba. Un paso más adelante y nos encontraremos con otro concepto, intuído desde antiguo y de reciente elaborado en la doctrina procesal, que es conocido bajo la denominación de motivo de prueba $(23)$.

(22) Instituciones de este concepto se tienen ya en las antiguas obras de BENTHAN, BONNIER, BALDI, MITTERMAIR y LESSONA.

(23) Aquí, sin embargo, es necesario que aclaremos exactamente el sentido de nuestras palabras. El concepto de motivo de prueba ha sido individualizado $\mathrm{y}$ aislado en algunas obras de Derecho proce- 
En efecto, no es difícil observar que nada tienen que ver, ni por su estructura, ni por su función, las razones que impulsan al órgano jurisdiccional a creer o al legislador a imponer un hecho con los medios ni con la materia de prueba hasta aquí examinados. El medio es, generalmente, la persona o cosa que suministra al órgano jurisdiccional la materia de prueba. La materia es el elemento presentativo, representativo 0 indicativo del hecho a probar, proporcinado al Juez por el medio. El motivo, por el contrario, la circunstancia o circunstancias que determinan la actitud del juzgador sobre la veracidad o falsedad de la materia.

Tres conceptos, pues, profundamente diversos en el plano lógico, si bien en la práctica no es extraeno encontrar entre ellos frecuentes interferencias (24).

Para hacer más clara la idea, basta que la ilustremos con unos sencillos ejemplos. En el caso de que en el proceso se efectúe prueba testifical, medios de prueba serán los testigos; materia, los testimonios por ellos proporcionados; motivos, la

sal civil (en la doctrina espanola, por ejemplo, v. GUASP: Derecho... cit., pág. 348, y PRIETO-CASTRO: Manual, pág. 391), en otras está claramente implícito. CARNELUTTI: Prova civile y Sistema, t. I, pág. 730 y ss.), y sobre todo su proyección sobre la veracidad de la materia de prueba cuenta con una abundante bibliografía especialmente extensa en relación a la crítica experimental del testimonio (V. CARNELUTTI: Prove civile e prove penali, "Riv. Dir. Pr. Civ." A. IV. núm. 1, part. 2.a páginas 3 y 35; Contro la prova testimoniale, "Riv. Dir. Pr. Civ." A. III, número 2, págs. 17 y ss.; La critica della testimonianza, Studi V, III, págs. 351 y ss. FIORE Manuale di Psicologia Giudiciaria, 1911 CALLIER: La valeur du temoignage, 1907. VAN DER ELST: La valeur du temoignage, in "Journal des Tribunaux Belgues" 1907 pág. 1225. DATINO: La psicología dei testimoni, 1909. MUSATTI: Elementi di psicologia della testemonianze, 1931. GORPHE: La Crítica del testimonio. RUIZ FUNES, 1933...). Pero lo que no ha sido jamás realizado y nosotros intentaremos efectuar después es situar el concepto en el lugar que sistemáticamente le corresponde dentro de la teoría general de la prueba, examinar cuidadosamente su naturaleza y realizar una clasificación que distinga y agrupe sus diversas especies.

(24) Algunas de estas interferencias fueram ya brevemente indicadas (v. la nota 14). Otras serán puestas de relieve más adelante. 
probidad, imparcialidad y actitud seguida por cada uno al hacer la declaración, que pueden inducir al Juez a dar fe a lo por ellos declarado. Si se trata de prueba documental escrita, el medio de prueba es el documento; la materia, la declaración que en el mismo se contiene; el motivo, el conjunto de circuns tancias que pueden llevar al Juez al convencimiento de la autenticidad y la veracidad de su contenido. La casuística podría aquí hacerse interminable. No sería difícil tampoco realizar, de modo más extenso y cuidado, una fina disección del fenómeno. Pero, puesto que volveremos más adelante a insistir sobre el mismo argumento, creemos que, para el estudio de la dirámica de la libre apreciación de la prueba en la jurisdicción civil, servirán sobradamente estos ligerísimos esbozos.

Dijimos al principio, y hemos venido reiteradamente repetiendo como un ritornello después, que la libre apreciación de la prueba es un fenómeno particularmente complejo. Poco a poco, sin embargo, con labor atenta, mesurada y serena, hemos ido penetrando en los secretos de su estructura. Algumas de las piezas fundamentales de tan singular mecanismo están ya completamente desmontadas e individualizadas. Pero pecaríamos de ingenuos si, con los conocimientos hasta aquí adquiridos, intentásemos desvelar todos sus arcanos.

Vimos como, para la determinación jurídica de ciertos hechos, el Juez ha de servirse de personas o de cosas - medios de prueba -, en las que, a los efectos de la prueba, cabe aislar elementos - materia - en cualquier modo reconstructivos del tema y elementos - motivos - fundamentalmente determinantes de la convicción.

\section{ACTOS DE ASUNCIÓN DE PRUEBAS}

Sin embargo, el haber individualizado dentro del área más extensa del medio de prueba dos conceptos tan interesantes como los ya citados no nos da derecho a pensar, ni mucho menos, que la meta ha sido alcanzada. Basta, por el contrario, una ligera observación de la realidad procesal para que nos percatemos de que estamos tan sólo en la mitad del camino. Los medios, la materia, los motivos de prueba (entidades ob- 
jetivas con aptitud para, en cualquier modo, presentar, representar o indicar los hechos que han de ser jurídicamente fijados por el Juez), no basta con que existan; es necesario, absolutamente necesario, además, que, puestos en contacto con el órgano jurisdiccional del Estado, le proporcionem a éste aquellas percepciones, que, adecuadamente elaboradas, serán la base de la decisión que pronunciará más tarde.

No basta, pues, con que exista una persona que haya presenciado la comisión de un asesinato, no es suficiente, tampoco, con que en documento notarial se haya extendido un contrato de compraventa. En uno y otro caso es absolutamente imprescindible, además, que tanto el testimonio como el contenido del documento sean conocidos por el órgano encargado de decidir el proceso en el que dicho hecho tiene relevancia. Sólo a través de ese conocimiento podrán, más tarde, los medios, la materia o los motivos de prueba influir en la determinación del Juez.

Hemos llegado asi a superar otra etapa de nuestro trabajo. Poco a poco, pausadamente, vamos descubriendo matices y facetas que nos ayudarán más tarde a la mejor comprensión del fenómeno de la libre apreciación.

El medio, la materia y los motivos de prueba - lo hemos visto - no son suficientes para explicar toda la mecánica de lє actividad probatoria. En todo caso es imprescindibie que los elementos que los medios de prueba pueden potencialmente suministrar sean en acto conocidos por el Juez. Se requiere, pues, en este sentido una actividad específica del órgano jurisdiccional del Estado. Se requiere, en definitiva, que el testigo sea escuchado, que el documento escrito sea leído y que la cosa sujeta a reconocimiento sea efectivamente inspeccionada. Y es precisamente a través de esta actividad cómo la eficacia potencial de los medios de prueba se transforma en eficacia actual y efectiva en el proceso. Sin ella carecerían en absoluto de virtualidad.

El concepto, pues, aparece claro. La palabra capaz de designarlo goza, asimismo, de una cierta tradición en lengua- 
je científico procesal (25). No será, pues aventurado tratar ahora de perfilar el fenómeno diciendo que medio de asunción de prueba es la actividad a través de la cual llega a conocimiento del órgano jurisdiccional del Estado los elementos que, más tarde, le servirán para fijar la existencia o inexistencia juridica de los hechos que componem el tema de prueba. Su estudio, especialmente a la hora de examinar diferencias, interferencias y afinidades que ligan esta actividad a la de incorporación del material probatorio, estaría lleno de ángulos sugestivos e interesantes (26). Pero tampoco podemos detenermos a realizarlo. Para la mejor comprensión de la dinámica de la libre apreciación de la prueba en la jurisdicción civil basta con que quede bien clara la idea de que, sin esa cierta actividad del órgano jurisdiccional del Estado que hemos designado como acto de asunción, los elementos de convicción que pueden suministrar los medios de prueba carecerían de relevancia en el proceso.

\section{REGLAS DE EXPERIENCIA}

De esta manera, muy ligeramente, es cierto, pero con bastante claridad, quedan así señaladas las categorías fundamentales, los conceptos claves, que es necesario construir para el adecuado entendimiento de lo que podríamos llamar la dinámica externa de la apreciación (27). A partir de este momento nuestra investigación debe penetrar más hondo; el mundo desconocido y maravilloso del alma del hombre se abre ante nosotros. Las dificutades, pues, aumentan y el esfuerzo para encontrar la palabra que exprese adecuadamente la idea se hace más penoso. Los actos de asunción de la prueba son preci-

(25) CHIOVENDA, sin embargo, hablada de procedimientos probatorios: Principios... cit., pág. 315).

(26) De todas formas queremos subrayar la extraordinaria importancia de esta distinción.

(27) CARNELUTTI ha hablado con frecuencia de la fase perceptiva y de la fase deductiva de la valoración probatoria. Así, por ejemplo, v. Sistema... cit., págs. 497 y ss. 
samente las puertas que separan y unen, al mismo tiempo, lo objetivo y lo subjetivo de apreciación. Por ellos, el órgano jurisdiccional del Estado, el sujeto que ha de efectuar el juicio valorativo, conoce y percible los elementos que, adecuadamente, reelaborados, determinarán más tarde su decisión. Antes de la asunción sólo existe - pura objetividad - el medio de prueba, despues de la asunción sólo encontramos subjetividad pura, procesos psíquicos. Los actos de asunción resultan así el punto de enlace entre lo objetivo y lo subjetivo de la apreciación.

Como hace muy poco insinuábamos, el análisis de esta fase del fenómeno valorativo resulta particularmente penoso. Debiendo examinar el desarrollo de puros procesos psíquicos, la introspección es el único medio que poseemos ,para poder reconstruir el camino que siguió el Juez en la elaboración de su raciocinio. Y este desdoblarse de la psique en sujeto observante y objeto observado está siempre erizado de dificultades y asperezas: sólo mediante un violento esfuerzo intelectual hacer conscientes y perceptibles fenómenos cuyo desarrollo se oculta, por regla general, tras los velos de nuestro subconsciente $(28)$.

$\mathrm{Y}$, puesto que la introspección es el único camino que podemos seguir para obtener le deseada meta, procedamos, ante todo, con orden. La asunción se ha realizado ya. Todos los actos externos que el órgano jurisdiccional tenía que cumplir han sido efectuados. Por tanto, al Juez sólo le resta afrontar el raciocinio valorativo, es decir, la apreciación de la prueba en sentido estricto. ¿Qué sucede entonces? El órgano jurisdiccional, esto es claro, tiene necesariamente que pronunciarse por la existencia o la inexistencia jurídica del tema de prueba. Es decir, ha de afirmar, o que el hecho controvertido existe, o que no existe, o que, por insuficiencia de pruebas, tiene que considerarlo como si no existiea (29). Pero ¿qué sucede en-

(28) Es necesario no olvidar que tal vez esta misma dificultad metódica sea la causa del retraso de las ciencias del espíritu en relación con el desarrollo extraordinario, modernamente alcanzado por las ciencias técnicas. 
tre la asunción de la prueba y esta afirmacion? ¿A través de qué desconocido proceso mental pasa el Juez de la percepción de los elementos de convicción, que el examen de los medios le proporciona, a la clara determinación del hecho? Este es precisamente el enorme problema.

Los juristas nos dirán que, en unos casos, el órgano jurisdiccional tiene que considerar como ciertos, por imperativo de una imposición normativa, los hechos que se encuentran avalados por el resultado de una específica prueba. Esta es la apreciación reglada, que, por exceder del tema de nuestro estudio, no podemos detenermos a considerar. Pero en otros supuestos, sin embargo - y éste es el fenómeno concreto objeto de nuestro trabajo - , la determinación de los hechos la realiza el Juez de acuerdo con la convicción que libremente se ha formado sobre los mismos, reelaborando en modo absolutamente personal los materiales probatorios que le fueron suministrados.

Precisamente examinar el proceso a través del cual se lleva a caba esa reelaboración es lo que a nosotros, ahora nos interesa.

Sin duda alguna la apreciación de la prueba es una operación mental - raciocinio —, que se concluye con la afirmación - juicio - de la existencia o inexistencia jurídica de un hecho. Proceso psíquico, por consiguiente, que, como es natural en todo raciocinio, salta de lo desconocido - elementos suministrados por los medios de prueba - a lo desconocido - hecho probado - Ahora bien: ¿cómo dar este salto? ¿Cómo pasar, sin más, de lo desconocido a lo ignoto? ¿Cómo atravesar dos laderas separadas por sima tan profunda, sino a través de un puente, de una pasarela, de algo consistente, real, conocido también que las una? ¿Cómo, en definitiva, puede el Juez convenserse del hecho a probar mediante el examen de los medios de prueba?

(29) En esta última hipótesis la mecánica de la carga de la prueba juega un papel relevantísimo. 
Vagamente vamos intuyendo la existencia de un elemento que, cuando quede perfectamente aislado e individualizado, nos proporcionará la solución de muchos enigmas. Así, en efecto, vislumbramos que si el Juez puede, a través del testimonio, llegar a la afirmación del hecho testimoniado, es porque su experiencia, su saber o el saber que otros hombres más expertos en la materia le han proporcionado, le indican, que, en determinadas circunstancias, puede prestarse fe a las declaraciones humanas. Este saber, estos conocimientos que le sirven para verificar la verdad de los elementos probatorios que han sido aportados por los medios de prueba, son los que, desde STEIN, vienen siendo conocidos en la doctrina procesal bajo la denominación de reglas de experiencia (30). Ya la palabra elegida para designar el concepto es bastante reveladora de su contenido. No se puede, en efecto, negar que en la mente del hombre, como precipitado de su experiencia individual, existen una serie de reglas, de normas de valoración y de crítica, con las que enjuicia en todo caso las sensaciones y percepciones presentes, uniéndolas con elementos del pasado o del futuro. Así, por ejemplo, por sus conocimientos de Medicina Legal el doctor que examina un herida sabe que su paciente ha sido atacado con un arma blanca de determinadas características. Del mismo modo, el astrónomo, que conoce las leyes celestes y observa la situación de los astros en el firmamento, está en condiciones de predecir un eclipse de luna. Pues bien: ese conjunto de conocimientos genéricos, de saberes más o menos técnicos y variables, según las épocas, los medios sociales y las condiciones peculiares de las personas, ese complejo de normas a veces casi inconscientes de valoración y de crítica son las reglas de experiencia, trampolín desde el que el hombre salta, en ágil pirueta intelectual, del presente limitado de su individual experiencia a las aguas más amplias del pasado s del futuro.

(30) En esta materia es fundamental la obra de STEIN: Das private Wissen Richters. 
Por ellas el órgano jurisdiccional del Estado está en condiciones de llegar, a través de la percepción de los elementos probatorios que el examen de los medios le proporciona, a la determinación de los hechos que constituyen el tema de prueba (31).

Sin perjuicio de realizar más adelante una más detenida eilaboración del concepto, podemos, ahora, de modo aproximativo, decir que las reglas de experiencia, en el caso de la libre apreciación, son las máximas formadas con la colaboración técnica de un experto o libremente elaboradas en la conciencia del Juez, de cuya confrontación con los motivos y la materia de prueba nace la actitud del juzgador en torno a la verdad o falsedad del hecho a probar.

\section{FUENTES DE PRUEBA}

Otro concepto ha quedado así perfectamente aislado e individualizado. Con ello hemos dado un paso enorme para la total comprención de la libre apreciación de la prueba en la jurisdicción civil.

Podemos afirmar incluso que todos los elementos subjetivos y objetivos que intervienen en esta operación intelectual han sido ya cuidadosamente separados y caracterizados. Pero puesto que se trata de un raciocinio que se concluye con un juicio de afirmación jurídica de hechos, es natural que no sea suficiente para nuestra investigación, la delimitación de los elementos que la componen hasta aquí realizada, si no la acompañamos de un análisis de su contenido. Esto es precisamente Ic que ahora deseamos efectuar.

La apreciación de la prueba es, en efecto, una operación mental en la que los materiales probatorios aportados por el examen de los medios de prueba son reelaborados, a la luz de las reglas de experiencia, de modo que sobre ellos el órgano juris-

(31) V. CARNELUTTI: La prova... cit., 1.a ed. págs. 79 y ss.; Sistema... cit., t. I, págs. 498 y ss., y Instituzioni... cit., pág. 224. 
diccional del Estado debe formar su convicción acerca de la existencia o inexistencia de los hechos que componen el tema de prueba. Pero que se trate de una operación mental en todo caso, no quiere decir que tenga siempre la misma estructura.

En efecto, la prueba, como ya dijimos en páginas anteriores, puede ser directa, histórica o crítica, según que la materia de prueba tenga carácter presentativo, representativo o indicativo del hecho a probar. $\mathrm{Y}$ no se necesita ser especialmente agudo para comprender que, en cada uno de esos diversos supuestos, la operación mental, a través de la cual el Juez llega a formar su convicción sobre los hechos, es profundamente diversa.

\section{a) En la prueba directa.}

En el primer caso, puesto que hecho a probar y medio de r,rueba coinciden, se trata simplemente de una sencilla percepción. Aquí la importancia de los elementos probatorios - materia y motivos - suministrados por los medios de prueba es tan grande, tan relevante, tan decisiva, que la intervención de las reglas de experiencia aparece casi por completo oscurecida (32).

Sin embargo, no se trata más que una falsa apariencia. En éste como en los restantes supuestos las reglas de experiencia intervienen para dar a las impresiones que continuamente nos llegan del exterior su preciso valor. Así, por ejemplo, porque conocemos las leyes de la refracción sabemos que la vara, casi totalmente introducida en el agua, no está doblada a pesar de su apariencia.

(32) Así, por ejemplo, sucedió a CARNELUTTI al tiempo de redactar su Prova civile. Este error fué más tarde superado por él. En todo caso la prueba directa no es una pura operación sensorial, sino también intelectiva $\mathrm{y}$ son siempre las reglas de experiencias las que fijan el valor de la percepción. 


\section{b) En la prueba histórica.}

En el segundo caso, la operación mental, el juicio valorativo en una palabra, gana complejidad. La materia de prueba no nos presenta, sino que nos representa el hecho a probar. Por ello, el órgano jurisdiccional del Estado no percibe el tema de prueba, sino una representación del mismo. Al contrario de lo que antes sucedía, aquí medio de prueba y hecho a probar son profundamente diversos. Como de la percepción de la representación el Juez tiene que pasar a la determinación deI hecho representado, el juicio valorativo es ahora muchísimo más complejo de lo que fuera en la prueba directa. Antes bastaba al órgano jurisdiccional, puesto que el hecho a probar estaba ante él constatar a través de las reglas de experiencia la exactitud de su percepción. Ahora necesita, a la luz de idénticas normas, no sólo fijar el alcance de la percepción, sino, además, examinar la idoneidad de la representación para determinar el hecho representado (33). De este modo, lo que es purá operación mental del Juez gana extensión y complejidad, y puesto que lo fundamental de este proceso lógico está en pasar de la percepción del hecho representativo a la determinación del hecho representado, haremos bien en denominar paradigmáticamente representación a la operación mental a través de la cual se realiza la prueba histórica. Esta operación es lo hemos afirmado ya - bastante más compleja de la percepción característica de la prueba directa, pero no tiene todavía la extraordinaria complicación de la presunción que implica toda prueba crítica.

c) En la prueba crítica.

En este último supuesto, la materia de prueba, ni presenta, ni representa el hecho a probar; sencillamente lo indica. Y

(33) Un puesto de honor en materia de prueba representativa corresponde al insigne profesor CARNELUTTI, que a través de sus obras fundamentales y en múltiples artículos de 'revista, ha contribuído como ninguno a aclarar los enormes problemas que plantea este tipo especial de prueba. 
de esta indicación se puede pasar a la afirmación de su existencia, en tanto en cuanto las reglas de experiencia le reconozcan eficacia bastante para determinar aquella conclusión. El tema de prueba no está, en este caso, ni presentado ni representado ante el órgano jurisdiccional; éste debe sencillamente presumirlo, en base a hechos distintos del tema de prueba, pero relevantes para fijarlo, que le han sido proporcionados por el examen de los medios (34).

Examinemos con un cierto detenimiento el modo como se desarrolla esta operación intelectual. Ante todo, no olvidemos que las personas o cosas son utilizadas en el proceso como medios de prueba en cuanto presentan o representan inmediatamente un hecho. Este hecho presentado o representado por el medio de prueba puede coincidir o no coincidir con el hecho objeto de prueba; si coincide, nos encontramos sencillamente ante casos de prueba histórica o prueba directa. Si no coincide, y puesto que de algún modo tiene que ser relevante para la prueba del tema, el hecho probado ha de ser, solo o con otros, e! indicio del que aquél pueda inducirse. De este modo, la operación mental, el raciocinio, a través del cual el órgano jurisdiccional del Estado llega a la determinación de los hechos, se hace muchísimo más complejo. El Juez en este supuesto no sólo ha de convencerse de la existencia o inexistencia del hecho inmediatamente presentado o representado por el medio de prueba, sino, además, inducir o deducir - presumir, en todo caso - la existencia o inexistencia de los hechos que componen el tema de prueba. Es decir, no sólo ha de comprobár, como en el caso de la prueba derecta, la exactitud de la percepción o, como en el supuesto de la prueba histórica, examinar, además, la idoneidad de la representación para determinar el hecho representado, sino que necesita, incluso, una vez fijado el hecho directamente presentado o representado por los medios de prueba, saltar de él, en pura cabriola intelectual, al que constituye objeto de la instrucción probatoria. Por ello pode-

(34) V. también CARNELUTTI: Sistema... cit., t. I, págs. 711 g ss. 
mos decir, que, en la prueba crítica, la materia de prueba inmediatamente presenta o representa el hecho indiciario, remotamente indica el hecho objeto de prueba.

De este modo acabamos de ver, reducidos a sus esquemas típicos, los tres tipos de operaciones mentales a través de las cuales el órgano jurisdiccional del Estado llega a la determinación de los hechos. Hasta ahora, aunque ya en diversas ocasiones se ha tratado de aislar el fenómeno (35) e incluso se ha encontrado para designarlo - fuente de prueba - una palabra que por su mayor aceptación parece va a prevalecer definitivamente en la doctrina procesal (36), no se han sacado todos los frutos que de esta observación, de la individualización y elaboración de este concepto podrían haberse obtenido.

De manera que, incluso después de definir las fuentes de prueba como las operaciones mentales a través de las cuales el órgano jurisdiccional fija la eficacia de los medios de prueba empleados en el proceso, o se sigue considerando la presunción como un medio probatorio (37), o no se han puesto suficientemente de relieve las otras operaciones intelectuales percepción y representación - que, con la presunción, agotan esta categoría (38). Las fuentes de prueba, operación lógica, como hemos dicho, es otro de los conceptos que ha sido también perfectamente individualizado y aislado. De este modo queda así realizado, en la forma esquemática que por exigencias del tema habíamos prometido, el estudio de la dinámica de la libre apreciación de la prueba en la jurisdicción civil.

(35) V. especialmente CARNELUTTI en La prova civile. Pero él, para designar el concepto, emplea la palabra medios de prueba.

(36) V. GUASP: Derecho... cit., pág. 347).

(37) PRIETO-CASTRO: Manual... cit., pág. 364 y ss. GUASP: Comentarios... cit., t. II, v. I, 2.a part. págs. 450 y ss. Derecho... cit., págs. 445 y ss. PLAZZA: Derecho... cit., t. I, págs. 521 y ss.

(38) Hacer entrar junto a la presunción, ya no considerada como un medio de prueba, los otros dos tipos de fuente de prueba que completan el concepto es la consecuencia natural implícita en la idea de fuente por nosotros defendida, pero jamás deducida, que sepamos, en una obra procesal. 


\section{CONCLUSIONES}

Paso a paso hemos ido atentamente observando el mecanismo para tratar de individualizar y distinguir las piezas que componían su estructura y que, adecuadamente unidas las unas a las otras, creaban la perfecta concreción del todo. Así, vimos que, para la realización de sus fines - determinación de la existencia o inexistencia del hecho controvertido - el órgano jurisdiccional del Estado se servía, ante todo, de personas o de cosas: medios de prueba.

Estas personas o cosas le proporcionaban elementos de diverso valor probatorio y distinta estructura, que individualizamos bajo la denominación de materia y motivos de prueba. Llegados unos y otros a conocimiento del Juez, mediante actividades específicas de éste - actos de asunción -, eran puestos en contacto con las reglas de experiencia del mismo, y a través de una compleja operación mental - fuentes de prueba - se conseguía, mediante la convicción, la finalidad perseguida: determinar la existencia o inexistencia de los hechos controvertidos.

Medio de prueba, materia de prueba, motivo de prueba, reglas de experiencia y fuentes de prueba son, así, los conceptos que hemos ido delineando a medida que avanzábamos en nuestro estudio. Que se trata de conceptos diferentes, reflejo fiel de una realidad compleja y no distinciones nacidas de un puro gusto a la elucubración bizantina, lo demuestra el sencillo examen de su diversa naturaleza; los medios de prueba son siempre una persona, una cosa o, excepcionalmente, una acción; la materia, un elemento de carácter presentativo, representativo o indicativo del hecho a probar contenido en el medio; los motivos, circunstancias de credibilidad; las reglas de experiencia, normas de apreciación, y las fuentes de prueba, operaciones mentales. Se trata, pues, de distintas categorías conceptuales que responden también a realidades diversas. 
Si esto no fuera suficiente para convencernos de esta verdad, observemos la realidad procesal y veremos como, en aquellos casos en que las diferencias son obstensibles, hasta en la práctica se conocem con nombres distintos fenómenos y elementos que se intuyen diversos.

Así, por ejemplo, cualquier práctico del Derecho distingue perfectamente el confesante, de la confesión y de la absolución de posiciones; el testigo, del testimonio y del examen testifical; el perito, de la pericia y de la prueba pericial. Lo que ocurre es que en otros casos - reconocimiento judicial, por ejemplo - la distinción no es ya tan neta, y como, por otra parte, el lenguaje jurídico, ante la menor evidencia del fenómeno, no ha sentido la necesidad de crear voces que designen de modo distinto fenómenos que son asimismo diferentes, en la práctica y hasta en la ciencia y en el Derecho positivo se engloban, bajo una denominación adecuada al lado más relevante del fenómeno, elementos y actividades que son profundamente diversos (39).

Urge, pues, para terminar de una vez con la terrible confusión que en materia tan importante se vea aflorar por todas partes, primero, colocar cada concepto en el lugar que sistemáticamente le corresponde, y, segundo, completar el lenguaje procesal para evitar que su insuficiencia dé lugar a oscuridades e incongruencias.

Ambas exigencias tratamos de satisfazer, brevemente, con el cuadro de la página anterior.

(39) Así, por ejemplo, sucede en el reconocimiento judicial las presunciones y documentos. En el reconocimiento judicial el medio de asunción de prueba - reconocimiento en sentido estricto - por su enorme relieve, absorbe y esconde los otros elementos que intervienem en este tipo de prueba. En las presunciones, por el contrario, es la fuente de prueba el elemento que por su relevancia oculta a todos. $\mathrm{Y}$ por último, en la prueba documental el medio - documento - es el aspecto más relevante del fenómeno. Se impone, pues, completar el lenguaje jurídico para aclarar y aislar las diversas fases $\mathrm{y}$ elementos del fenómeno probatorio. 


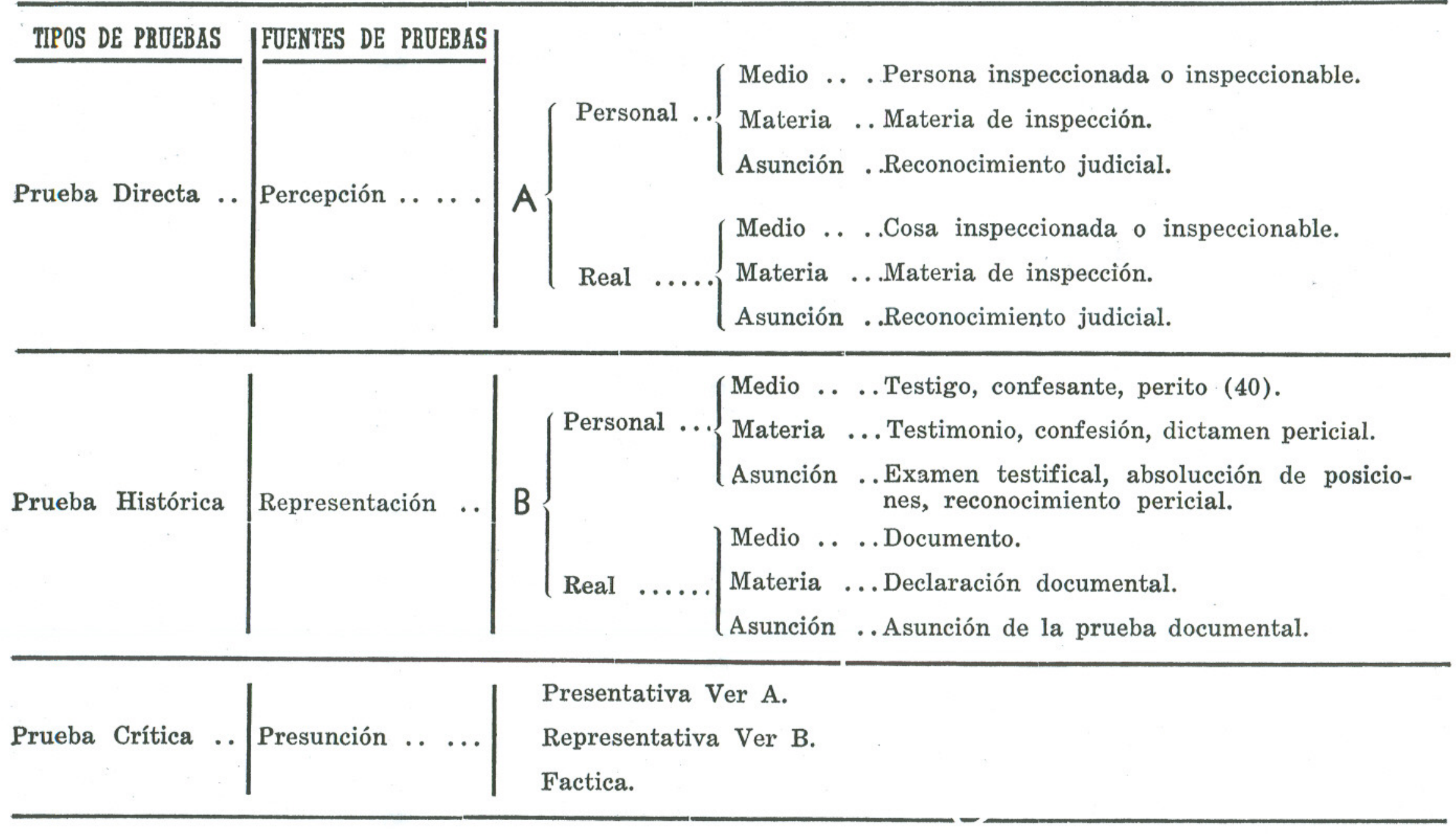

(40) Conviene, sin embargo, observar que la pericia puede considerarse un medio especial de prueba, puesto que trata de proporcionar al Juez elementos encuadrables en la premisa mayor del silogismo probatorio. 
Hacer notar los errores que, lo mismo en el Derecho positivo (41) que en la más autorizada doctrina procesal antigua y moderna (42), ha ocasionado, tanto la no suficiente delimityación de los conceptos que hemos venido individualizando como el no haber sabido después extraer de ellos sus naturales e importantes consecuencias, sería una labor ingente por sus proporciones. Nosotros nos limitaremos aquí a señalar el hecho, dando, al mismo tiempo, por terminado el estudio de la dinámica de la libre apreciación de la prueba en la jurisdicción civil.

A) En Espana, el artículo 1.215 del C. c. dice: "Las pruebas pueden hacerse por instrumentos, por confesión personal del Juez, por peritos, por testigos $\mathrm{y}$ por presunciones." Es decir, el legislador espanol coloca en el mismo plano de los medios de prueba - instrumentos, peritos y testigos - una materia de prueba - la confesión -, un medio de asunción de prueba - la inspeción personal del Juez - y una fuente de prueba - las presunciones Mayor ataque a los principios lógicos, de acuerdo con los cuales debe ser realizada toda clasificación, difícilmente sería imaginable.

B) Ni siquiera la legislación italiana escapa a la crítica, puesto que después de hablar inteligentemente en los capítulos II y III del título que el Código civil dedica a las pruebas, de la prueba documental y de la prueba testifical (inteligentemente, decimos, porque con esta expreción amplísima no se liga a ningún particular elemento probatorio, respecto al cual los restantes miembros de la clasificación deberán, después, ser congruentes) dedica el capítulo III a las presunciones - fuentes de pruebas -, el capítulo V a la confesión - materia de prueba - y el capítulo VI al juramento - materia de prueba también - Incluso aquí la congruencia essencial para la perfección de toda classificación es una cualidad que no aparece por ninguna parte.

(41) Para ver la confusión existente en este punto, basta pensando que toda clasificación sólo es perfecta cuando sus miembros son congruentes con el criterio escogido para realizarla, observar las declaraciones del Derecho positivo. Entonces nos convenceremos de la falta absoluta de claridad de ideas sufrida por el legislador en materia de prueba.

(42) En este lugar no queremos hacer citas. Basta leer cualquier libro dedicado a esta materia para observar los errores que ahora criticamos. 